\title{
Anatomical Study of the Canalis Sinuosus in Chilean Individuals by Cone-Beam Computed Tomography
}

\author{
Estudio Anatómico del Canal Sinuoso en Individuos Chilenos \\ Mediante Tomografía Computarizada Cone-Beam
}

Nilton Alves ${ }^{1,2}$; Rodrigo Toro ${ }^{3}$; Ivonne Garay ${ }^{4}$ \& Naira Figueiredo Deana ${ }^{5,6}$

\begin{abstract}
ALVES, N.; TORO, R.; GARAY. I. \& DEANA, N. F. Anatomical study of the canalis sinuosus in chilean individuals by cone-beam computed tomography. Int. J. Morphol., 39(3):928-934, 2021.

SUMMARY: The canalis sinuosus (CS) is a double-curved bone canal in the anterior region of the maxilla. The CS contains a vasculonervous bundle consisting of the anterior superior alveolar nerve and its corresponding arteries and veins. The CS and its accessory canals (AC) have been little described in the literature and are often omitted in imaging evaluations before procedures in the region. The object of the present study was to evaluate the frequency of the CS and its AC in Chilean individuals, and to carry out a morphometric analysis of these anatomical structures by cone-beam computed tomography (CBCT) by sex, side and age range. CBCT examinations of 28 patients were studied, evaluating the presence, diameter and terminal portion of the CS. We also evaluated the presence and number of AC, and their terminal portion. The diameter of the AC was classified as greater or smaller than $1.0 \mathrm{~mm}$. Non-parametric tests were used for quantitative variables and chi-squared for qualitative variables. The SPSS v.27.0 software was used, with a significance threshold of $5 \%$. The CS was present in all the samples analysed, generally presenting a diameter greater than $1.0 \mathrm{~mm}$. Alterations were found, and the diameter could be greater depending on the segment evaluated, however it was not affected by sex, side or age range. The terminal portion of the CS is usually located adjacent to the region of the nasal cavity. The frequency of AC was very high, and the most common location was in the region of the upper central incisor; in $61.3 \%$ of cases their diameter ?1.0 mm. The high frequency of CS and $\mathrm{AC}$ shows the importance of carrying out a detailed imaging study before invasive procedures in the anterior region of the maxilla.
\end{abstract}

KEY WORDS: Canalis sinuosus; Accessory canal; Anterior superior alveolar nerve; Cone-beam computed tomography.

\section{INTRODUCTION}

The canalis sinuosus (CS) is a tortuous bone canal which originates in the infraorbital canal, slightly posterior of the infraorbital foramen, and continues to anterolateral until it reaches the anterior wall of the nasal cavity, inferior to the infraorbital margin (Jones, 1939). The CS then turns to medial and continues below the infraorbital foramen to the lateral wall of the nasal cavity where it curves downwards along the pyriform aperture to reach the anterior region of the maxilla (von Arx et al., 2013). The CS contains a vasculonervous bundle consisting of the anterior superior alveolar nerve and its corresponding arteries and veins (Jones; Alves\& Cândido, 2016). The anterior superior alveolar nerve is the longest nerve in the alveolar region (Jones; de Oliveira-Santos et al., 2013) and innervates the upper incisors and canines, the periodontal ligaments of these teeth, and the vestibular mucous of the region (Jones; Alves \& Cândido).
The frequency of the CS reported in the literature is very variable, ranging from $51.7 \%$ (Machado et al., 2016) to $100 \%$ of samples (Baena-Caldas et al., 2019). The CS is generally between 1 and $2 \mathrm{~mm}$ in diameter (Wanzeler et al., 2015), and its clinical importance is often underestimated. Failure to include it in planning or evaluation of treatment in the anterior region of the maxilla may determine increased risk of lesion to the anterior superior alveolar nerve and corresponding vessels.

Because of its high frequency, the CS is considered a normal anatomical structure. Nevertheless, its aperture in the anterior region of the maxilla may be considered an anatomical variation (accessory canal) (de Oliveira-Santos et al.) which may be related with the population studed (Gray et al., 1973).

\footnotetext{
${ }^{1}$ Center of Excellence in Surgical and Morphological Research (CEMyQ), Faculty of Medicine, Universidad de La Frontera, Temuco, Chile.

${ }^{2}$ Applied Morphology Research Centre (CIMA), Faculty of Dentistry, Universidad de La Frontera, Temuco, Chile.

${ }^{3}$ Master of Science Program, Mention Morphology, Faculty of Medicine, Universidad de La Frontera, Temuco, Chile.

${ }^{4}$ Center for Research and Innovation in Clinical Dentistry, Faculty of Dentistry, Universidad de La Frontera, Temuco, Chile.

${ }^{5}$ Center for Research in Epidemiology, Economics and Oral Public Health (CIEESPO), Faculty of Dentistry, Universidad de La Frontera, Temuco, Chile.

${ }^{6}$ Department of Paediatric Dentistry and Orthodontics, Faculty of Dentistry, Universidad de La Frontera, Temuco, Chile.
} 
Many dental procedures are carried out in the anterior region of the maxilla (Arruda et al., 2017); correct treatment planning and detailed anatomical knowledge of this region are fundamental to avoid injuries to the neurovascular structures present. The object of the present study was therefore to evaluate the frequency of the CS and its $\mathrm{AC}$ in Chilean individuals, and to carry out a morphometric analysis of these anatomical structures by cone-beam computed tomography (CBCT) by sex, side and age range.

\section{MATERIAL AND METHOD}

A descriptive, retrospective, observational crosssectional study was carried out. The sample was nonprobabilistic, by convenience. We examined all the CBCT images taken between May and October 2019 as part of the diagnosis and/or treatment planning of patients who attended the Teaching Clinic of Universidad of the Frontera, Temuco, Chile. All the patients involved in this study signed an informed consent which stated their free right to participate in the study or not, with no influence on their dental treatment. The study was approved by the Scientific Ethics Committee of La Frontera University, Folio No 058-19.

Cone-Beam Computed Tomography Examination. A PAX Zenith 3D CBCT (Vatech Co., Gyeonggi-Do, Korea) was used with a flat screen image detector and a field of view of $8 \times 6 \mathrm{~cm}$. The images were taken at $120 \mathrm{kVp}, 10$ $\mathrm{mA}$ and voxel size $0.12 \mathrm{~mm}$, exposure time 24 seconds. The $3 \mathrm{D}$ reconstructions were created by formatting the axial CBCT scanners in a local work station, using Ez3D Plus dental image software (E-WOO Technology Co. Ltd., Korea).
Sample. The sample consisted of CBCT examinations of Chilean individuals, of both sexes, with or without tooth loss in the anterior region of the maxilla, aged 15 years or more. Examinations were excluded of subjects who presented impacted teeth in the anterior region of the maxilla; previous maxillofacial surgery in the anterior region of the maxilla; pathological lesions in the anterior region of the maxilla; supernumerary teeth or low quality cone-beam computed tomography images.

The examinations were analysed considering sex, side and age range (15-29 years, 30-44 years and 45 years or more).

Measurements. Before taking the measurements, the investigator was calibrated by an experienced radiologist. The diameter of the CS was measured by by taking coronal crosssections $1 \mathrm{~mm}$ thick; it was measured in three segments: Segment 1 (S1): start of the CS, using a reference point fixed $25 \mathrm{~mm}$ behind the infraorbital foramen; Segment 2 (S2): immediately posterior of the bifurcation of the CS in the lateral margin of the pyriform aperture; Segment 3 (S3): terminal portion of the CS in the maxilla (Fig. 1). The length of the CS was measured by identifying its start and end points by sagittal and frontal cross-sections $1 \mathrm{~mm}$ thick. The terminal portion of the CS was classified in accordance with Wanzeler et al.: dental apex, adjacent to dental apex (indicating which tooth), nasal cavity, maxillary sinus or alveolar crest.

The presence and number of AC were evaluated (Fig. 2 ). The AC were classified as defined by de Oliveira-Santos et al., according to the region of their terminal portion: upper central incisor, between the upper central and lateral incisors, upper lateral incisor, upper canine, and adjacent to the incisive foramen (anterior, posterior or lateral). The diameter of the $\mathrm{AC}$ was measured in the terminal portion, using as reference its anterior, posterior, lateral and medial margins.
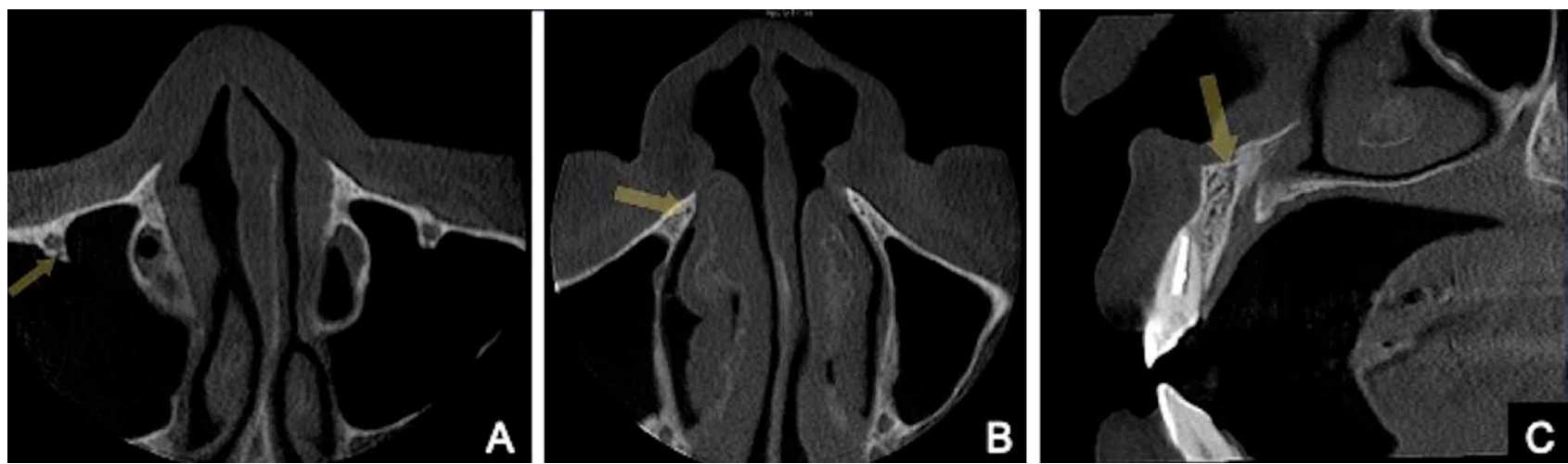

Fig. 1. A. Axial section CBCT image, showing the origin of the right canalis sinuosous, located posterior of the infraorbital foramen (arrow). B. Axial section CBCT image, showing the right canalis sinuosus posterior of its bifurcation in the lateral nasal margin of the pyriform aperture (arrow). C. Sagittal section CBCT image, showing the emergence of the right canalis sinuosus in the floor of the nasal cavity, close to the anterior nasal spine (arrow). 


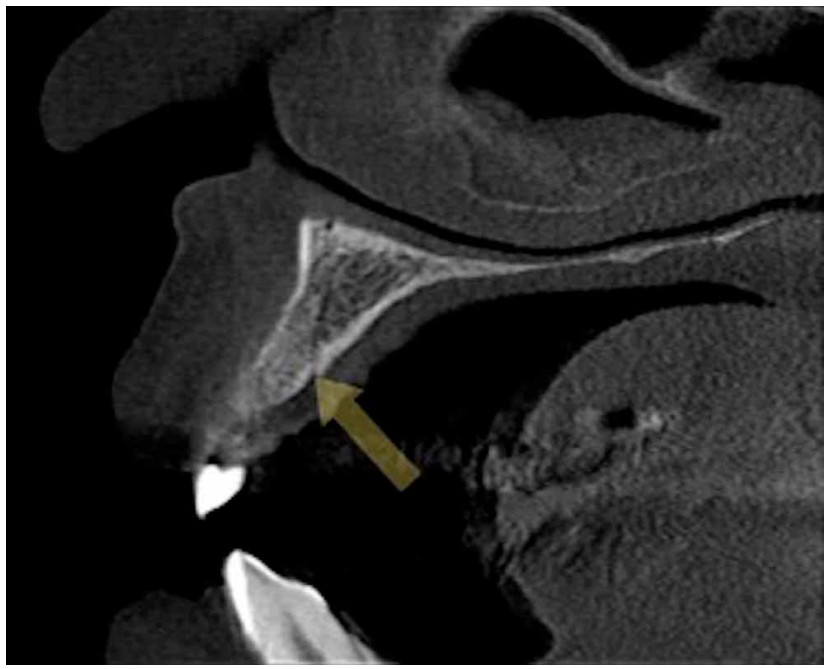

Fig. 2. Sagittal section CBCT image, showing an accessory canal (right side) in the palatal face of the region of the lateral incisor (arrow).

Statistical analysis. The intraclass correlation coefficient (ICC) and the kappa test were used for intra-observer analysis. The association was classified as poor (0.0), slight (0.01-0.20), regular (0.21-0.40), moderate (0.41-0.60), substantial (0.61-0.80) and almost perfect (0.81-1.00) (Landis \& Koch, 1977). Levene's test was applied to test homogeneity of variances and the Shapiro-Wilk test to analyse the normality of the data. Pearson'schi-squared test was used for qualitative variables. Wilcoxon's test was used for analysis between sides and the Mann-Whitney U test for analysis between sexes. The Kruskal-Wallis test was used for the analysis between age ranges and between segments of the CS. Spearman's correlation coefficient was used to analyse the relation between age $\mathrm{x}$ length of the canalis sinuosus. Pearson's correlation was classified as nil $(\mathrm{r}=0)$, very low $(0<\mathrm{r}<0.2)$, low $(0.2<\mathrm{r}<0.4)$, moderate $(0.4<\mathrm{r}<0.6)$, high $(0.6<\mathrm{r}<0.8)$, very high $(0.8<\mathrm{r}<1)$ and perfect $(\mathrm{r}=1)$ (Schober et al., 2018). The figures were created using the GraphPrism software. SPSS software v.27.0 was used for statistical analysis, with a significance threshold of $5 \%$.

\section{RESULTS}

Thirty-seven CBCT examinations were studied, of which nine were eliminated in accordance with the inclusion and exclusion criteria. One examination was excluded because the patient had a palatal fissure, one because the patient had supernumerary teeth, two because the patients presented unerupted teeth in the anterior region of the maxilla, one because the patient had a cyst extraction tube in the anterior region of the maxilla and four because the complete course of the CS could not be visualised. The final number of examinations included was 28 , six of male individuals and 22 of females. The mean age of the males was 41.33 years $( \pm 15.87)$ and of the females 42.59 years $( \pm 18.33)(\mathrm{p}=0.880)$. All examinations were analysed bilaterally. The intra-observer agreement index was higher than 0.80 for all the measurements.

Diameter of CS. The diameters of the CS were: Segment 1: mean $1.19 \mathrm{~mm}(\mathrm{SD}=0.20 \mathrm{~mm})$, median $1.20 \mathrm{~mm}$ (IQR=0.20 $\mathrm{mm})$; Segment 2: mean $1.38 \mathrm{~mm}(\mathrm{SD}=0.29 \mathrm{~mm})$, median 1.30 $\mathrm{mm}(\mathrm{IQR}=0.30 \mathrm{~mm})$; and Segment 3: mean $1.09 \mathrm{~mm}(\mathrm{SD}=0.20$ $\mathrm{mm})$, median $1.10 \mathrm{~mm}(\mathrm{IQR}=0.20 \mathrm{~mm})$. No statistically significant differences were observed between sexes, sides or age ranges in the analysis of the diameter in each segment $(\mathrm{p}>0.05)$.

The diameter of the CS in S2 was significantly larger than in S3, except for the age range 30-44 years. The diameter of the CS in S1 was significantly larger than in S3, in females, on the right side and in the age range 15-29 years. Finally, the diameter of the CS in S2 was larger than in S1 in females, on the left side and among individuals aged 45 years or more (Fig. 3).

No correlation was observed between S1, S2 and S3 for the diameter of the CS; there was a non-significant low positive correlation between $\mathrm{S} 1$ and $\mathrm{S} 2(\mathrm{rho}=0.082, \mathrm{p}=0.550)$, non-significant low negative correlation between $\mathrm{S} 1$ and $\mathrm{S} 3$ $($ rho $=0.025, \mathrm{p}=0.853)$ and non-significant slight positive correlation between $\mathrm{S} 2$ and $\mathrm{S} 3$ (rho $=0.215, \mathrm{p}=0.111$ ).

The diameter of the CS varied between $0.70 \mathrm{~mm}$ and $1.60 \mathrm{~mm}$ in the region of S1;82.1\% of the CS presented a diameter between 1.0 and $1.4 \mathrm{~mm}$, and only $8.9 \%$ presented a diameter greater than $1.5 \mathrm{~mm}$. In the region of S2, the diameter of the CS varied between 1.0 and $2.20 \mathrm{~mm} ; 66.7$ $\%$ of the CS presented a diameter between 1.0 and $1.4 \mathrm{~mm}$ and $33.3 \%$ presented a diameter greater than $1.5 \mathrm{~mm}$. In the region of S3, the diameter of the CS varied between 0.7 and $1.90 \mathrm{~mm} ; 75 \%$ of the CS presented a diameter between 1.0 and $1.4 \mathrm{~mm}$ and only $5.4 \%$ presented a diameter greater than $1.5 \mathrm{~mm}$. A higher percentage of CS with diameter between 1.0 and $1.4 \mathrm{~mm}$ was observed in Segments 1 and 3 . In the region of Segment two, $33.3 \%$ of the CS presented a diameter greater than $1.5 \mathrm{~mm}(\mathrm{p}=0.000)$.

Terminal portion of the CS. The nasal cavity was the region where the CS terminated with highest frequency (57.1\%), followed by the region of the alveolar crest $(16.1 \%)$ and the region adjacent to the apex of the upper central incisor (12.5 $\%)$. In $5.4 \%$ of the examinations, the terminal portion of the CS was observed in the region to lateral and anterior of the incisive foramen; and finally, the terminal portion of the CS in the region adjacent to the apex of the upper central incisor 


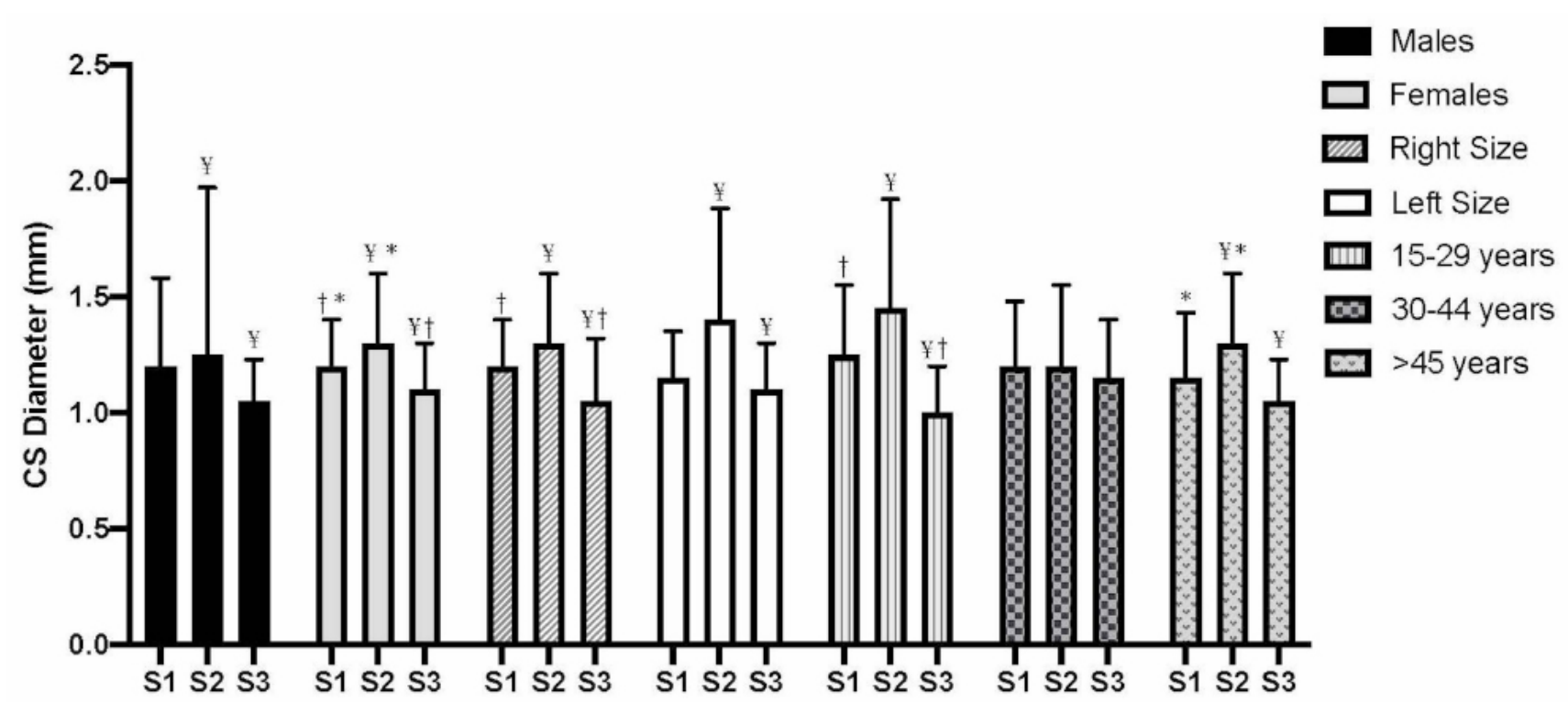

Fig. 3. Diameter of the CS by segment. The data are presented by sex, side and age range. * statistically significant difference between Segments 1 and 2 . $\dagger$ statistically significant difference between Segments 1 and 3. $¥$ statistically significant difference between Segments 2 and 3. S1: initial portion of the CS, using a reference point $25 \mathrm{~mm}$ behind the infraorbital foramen. S2: immediately posterior of the bifurcation of the CS in the lateral margin of the pyriform aperture. S3: terminal portion of the CS in the maxillary region.

presented the lowest percentage, with only $3.6 \%$. No statistically significant differences were found between sexes $(\mathrm{p}=0.109)$, sides $(\mathrm{p}=0.257)$ or age ranges $(\mathrm{p}=0.671)$.

Accessory Canals. In all the CBCT examinations analysed we observed the presence of at least one accessory canal (AC). There were three AC in $42.9 \%$ of cases, two AC in $25 \%$, four AC in $19.6 \%$; only one AC was observed in 7.1 $\%$ of examinations and five $\mathrm{AC}$ were found in $5.4 \%$ of cases.

A total of $163 \mathrm{AC}$ were observed; the region of the upper central incisors was the region with the highest percentage of $\mathrm{AC}(30 \%)$, and the region adjacent to the incisive foramen (lateral) the region with the lowest percentage (5.5 $\%)$; no $\mathrm{AC}$ were observed in the region adjacent to the incisive foramen (posterior) $(0.0 \%)$. The mean diameter of the $\mathrm{AC}$ was $1.01 \mathrm{~mm}(\mathrm{SD}=0.178 \mathrm{~mm})$, with a minimum of $0.70 \mathrm{~mm}$ and a maximum of $1.60 \mathrm{~mm}$; no statistical differences were found for the diameter of the AC by location. In $61.3 \%$ of examinations $(\mathrm{n}=100)$, the $\mathrm{AC}$ presented a diameter greater than $1.0 \mathrm{~mm}$; there was no association between location of the $\mathrm{AC}$ and diameter $>1 \mathrm{~mm}(\mathrm{p}=0.502)$ (Table I).

The left side (mean $1.05 \mathrm{~mm}, \mathrm{SD}=0.180 \mathrm{~mm}$; median $1.00 \mathrm{~mm}, \mathrm{IQR}=0.20 \mathrm{~mm}$ ) presented significantly higher values than the right side (mean $0.97 \mathrm{~mm}, \mathrm{SD}=0.169 \mathrm{~mm}$; median $1.00, \mathrm{IQR}=0.20 \mathrm{~mm})(\mathrm{p}=0.019)$. The percentage of AC with diameter $>1 \mathrm{~mm}$ was significantly higher in the left side (57 $\%)$ than in the right $(43 \%),(\mathrm{p}=0.011)$. The finding of significant differences between sides for the diameter of the $\mathrm{AC}$ was corroborated by analysis of Spearman's correlation, where a non-significant low positive correlation was found between the right and left sides for the diameter of the AC (rho=0.199, $\mathrm{p}=0.098$ ).

Table I. Percentage of AC with diameter greater than $1 \mathrm{~mm}$ : mean, median, minimum and maximum values of the AC by location. The data are presented in millimetres.

\begin{tabular}{|c|c|c|c|c|c|c|}
\hline Region & $\mathrm{n} / \%$ & $\begin{array}{l}\text { Mean }(\mathrm{SD}) \\
(\mathrm{mm})\end{array}$ & $\begin{array}{c}\text { Median } \\
(\mathrm{IQR})(\mathrm{mm})\end{array}$ & $\begin{array}{l}\text { Minim } \\
(\mathrm{mm})\end{array}$ & $\begin{array}{l}\text { Maxim } \\
(\mathrm{mm})\end{array}$ & $\begin{aligned} \mathrm{AC} & >1 \mathrm{~mm} \\
(\mathrm{n} & =100)\end{aligned}$ \\
\hline Upper canine & $19 / 11.6$ & $0.99(0.143)$ & $1.00(0.20)$ & 0.80 & 1.30 & $10 \%$ \\
\hline Upper lateral incisor & $43 / 26.4$ & $1.01(0.192)$ & $1.00(0.20)$ & 0.70 & 1.50 & $27 \%$ \\
\hline Upper central and lateral incisors & $28 / 17.2$ & $1.04(0.187)$ & $1.00(0.80)$ & 0.80 & 1.60 & $21 \%$ \\
\hline Upper central incisor & $49 / 30.0$ & $1.01(0.180)$ & $1.00(0.20)$ & 0.70 & 1.50 & $30 \%$ \\
\hline Adjacent to the incisive foramen (anterior) & $15 / 9.2$ & $1.00(0.183)$ & $1.00(0.20)$ & 0.80 & 1.40 & $8 \%$ \\
\hline Adjacent to the incisive foramen (lateral) & $9 / 5.5$ & $0.96(0.150)$ & $0.90(0.25)$ & 0.80 & 1.20 & $4 \%$ \\
\hline Adjacent to the incisive foramen (posterior) & $0 / 0.0$ & - & - & - & - & - \\
\hline
\end{tabular}


No statistically significant differences were found between sexes or between age ranges for the diameter of the $\mathrm{AC}(\mathrm{p}>0.05)$. In the analysis between sexes by location of the AC, a statistically significant difference was found only in the region of the upper central incisors, where the values found for males were higher than for females $(\mathrm{p}=0.001)$.

\section{DISCUSSION}

In our investigation we carried out an anatomical study of the CS in the Chilean population by CBCT, finding that the CS was present in $100 \%$ of cases, bilaterally. Previous studies have reported different results with lower percentages. Aoki et al. (2020) reported that the CS was present in $66.5 \%$ of cases in the Brazilian population, and was more frequently bilateral than unilateral. A similar percentage was reported by Anatoly et al. (2019), who found a total of $67 \%$ presence of CS in the Russian population, but with unilateral presence more common than bilateral. Wanzeler $\mathrm{et} \mathrm{al}$. report finding a frequency of $88 \%$ presence of CS in the Brazilian population, while Gurler et al. (2017), in a study in the Turkish population, declared that they found CS in all the examinations analysed, as in our study. We agree with Wanzeler et al. when they say that the high percentage of presence of CS shows that it is a normal anatomical structure, not an anatomical variation. It must therefore be considered when planning treatments in the anterior region of the maxilla to avoid accidents during procedures in this region.

Because the anterior region of the maxilla is a region where many dental interventions are carried out, it is also susceptible to accidents during treatment of pathologies or surgery in the region; the patient may suffer pain due to exposure of the CS (Lopes dos Santos et al., 2020) or during the insertion of implants, and neurosensory alterations may result from surgical procedures (Volberg \& Mordanov, 2019; Shintaku et al., 2020).

In the present study no differences were found between sexes or sides for the terminal portion of the CS, corroborating the studies of Wanzeler et al. and Manhães Junior et al. (2016). The terminal portion of the CS was observed most frequently in the nasal cavity, followed by the alveolar crest, and least frequently in the region adjacent to the apex of the upper central incisor, with no differences observed between sexes, sides or age ranges. Previous studies have reported different results, observing the terminal portion of the CS most frequently in the region adjacent to the upper central incisor (Aoki et al.; de Oliveira-Santos et al.; Machado etal.), or in the region of the upper lateral incisor and the canine (Manhães Junior et al.; Gurler et al.; Orhan et al., 2018; Anatoly et al.).

Gurler et al. state that the diameter of the CS was significantly larger in males than in females; this disagrees with the results found in our study, where we found no differences between sexes. On the other hand, these authors found no differences between sides, which agrees with both our investigation and the findings of Manhães Junior et al. Our results showed that the majority of CS have a diameter larger than $1.0 \mathrm{~mm}$, varying by segment analysed; this disagrees with the studies of Aoki et al. and Machado et al., who reported that $96 \%$ of CS presented a calibre of up to 1 $\mathrm{mm}$. A larger calibre for the CS was found in the region immediately posterior of the bifurcation of the canalis sinuosus in the lateral margin of the pyriform aperture (S2) in comparison with the initial and terminal portions of the CS. Furthermore, in our analysis of the diameter of the CS we found no correlation between these segments, showing that there are variations in the calibre of the CS during its course; this contrasts with the results reported by Aoki et al. and Wanzeler et al., who say that the diameter of the CS is similar throughout its length.

Our study in a Chilean population reported a larger mean diameter for the CS than did Wanzeler et al. in the Brazilian population, with $0.74-0.79 \mathrm{~mm}$ for the initial segment and $0.81 \mathrm{~mm}$ for the terminal portion. In our study the terminal portion (S3) of the CS was the segment that presented the smallest calibre, with mean of 1.09 , while S2 presented the largest calibre with $1.38 \mathrm{~mm}$. de Oliveira-Santos et al. and von Arx et al. found similar mean values to ours for the diameter in the region of S2, with $1.4 \mathrm{~mm}$ and $1.3 \mathrm{~mm}$ respectively.

Accessory Canals. After reaching the lateral wall of the nasal cavity, AC may diverge from the CS. We agree with Machado et al. who say that the AC of the CS is a frequent anatomical structure, since in our study at least one $\mathrm{AC}$ was found in every sample analysed; up to five $\mathrm{AC}$ were observed, the most frequent number being 3 , independent of sex, side or age range. Orhan et al. found a mean number of 4.6 AC, which generally ended in the region of the upper central incisor. Machado et al. report a frequency of 1-4 AC, with a mean diameter of $1.4 \mathrm{~mm}$, similar to the result of our study. The terminal portion of the $\mathrm{AC}$ was most frequently found in the region of the upper central incisors, corroborating the findings of von Arx et al.

In the present investigation, the diameter on the left side was larger than that on the right side, however other variables like sex and age did not influence the diameter of the AC; Machado et al. also observed no differences between 
sexes and between ages. These authors, who studied the Brazilian population, reported that only $20 \%$ of AC presented a diameter of at least $1.0 \mathrm{~mm}$ (Machado et al.), similar to the result reported by de Oliveira-Santos et al. in the Belgian population, with $15.7 \%$. In our study in a Chilean population, we found that $61.3 \%$ of the AC presented a diameter of at least $1.0 \mathrm{~mm}$. These differences may be related with the population studied, since some studies relate variations in the $\mathrm{CS}$ with an ethnic and/or demographic context (Gray et al.).

\section{CONCLUSIONS}

The CS normally presents a diameter greater than $1.0 \mathrm{~mm}$, which may vary over its course; it is greatest in the region of the bifurcation of the $\mathrm{CS}$ at the lateral margin of the pyriform aperture. The anatomy of the CS is not affected by sex, side or age range and the terminal portion of the CS is usually in the nasal cavity. In a high percentage of cases the CS presents $\mathrm{AC}$; it is common to find at least $3 \mathrm{AC}$ on each side. Most AC present a calibre of at least $1.0 \mathrm{~mm}$, and are larger on the left side, but with no effects of sex or age range. The terminal portion of $\mathrm{AC}$ to the $\mathrm{CS}$ is most frequently found between the upper central incisors, followed by the region of the upper lateral incisor. The high frequency of $\mathrm{CS}$ and $\mathrm{AC}$ shows that a detailed imaging study is required before undertaking invasive procedures in the anterior region of the maxilla.

ALVES, N.; TORO, R.; GARAY. I. \& DEANA, N. F. Estudio anatómico del canal sinuoso en individuos chilenos mediante tomografía computarizada cone-beam. Int. J. Morphol., 39(3):928-934, 2021.

RESUMEN: El canal sinuoso (CS) es un canal óseo que presenta doble curvatura, ubicado en la región anterior de maxila. El CS contiene un paquete vásculonervioso formado por nervio alveolar superior anterior, arterias y venas correspondientes. El CS y sus canales accesorios (CA) han sido poco descritos en la literatura y muchas veces son omitidos en evaluaciones imagenológicas previas a procedimientos en la región. El objetivo del presente estudio fue evaluar la frecuencia del CS y de sus CA en individuos Chilenos, bien como realizar un análisis morfométrico de estas estructuras anatómicas mediante tomografía computarizada conebeam (TCCB) según sexo, lado y rangos etarios. Fueron evaluados exámenes de TCCB de 28 pacientes. Se evaluó la presencia, diámetro y porción terminal del CS. Se evaluó la presencia del CA, cantidad y porción terminal. El diámetro del CA fue clasificado en mayor o menor a 1,0 mm. Se uti- lizaron pruebas no paramétricas para variables cuantitativas y chi-cuadrado para variables cualitativas. Se utilizó el software SPSS 27.0, considerándose umbral de significación de $5 \%$. El CS estuvo presente en todas las muestras analizadas, presentando en general un diámetro mayor a 1,0 mm. El diámetro del CS sufre alteraciones pudiendo ser mayor dependiendo de la región evaluada, sin embargo no se ve afectado por sexo, lado o rangos etarios. La porción terminal de CS suele ubicarse adyacente a la región de cavidad nasal. La frecuencia de CA es muy alta, en un $61,3 \%$ presentan diámetro ?1,0 $\mathrm{mm}$, siendo la región de incisivo central superior su ubicación más común. La alta frecuencia de CS y de CA demuestra la importancia de realizarse un detallado estudio imagenológico previo a procedimientos invasivos en región anterior de la maxila.

PALABRAS CLAVE: Canal sinuoso; Canal accesori; Nervio alveolar superior anterior; Tomografía computarizada cone-beam.

\section{REFERENCES}

Alves, N. \& Cândido, P. L. Anatomía para o Curso de Odontologia Geral e Específica. $4^{\mathrm{a}}$ ed. São Paulo, Gen-Santos, 2016.

Anatoly, A.; Sedov, Y.; Gvozdikova, E.; Mordanov, O.; Kruchinina, L.; Avanesov, K., Vinogradova, A.; Golub, S.; Khaydar, D. Hoang, G.N.; et al. Radiological and morphometric features of canalis sinuosus in Russian population: cone-beam computed tomography Study. Int. J. Dent., 2019:2453469, 2019.

Aoki, R.; Massuda, M.; Zenni, L. T. V. \& Fernandes, K. S. Canalis sinuosus: anatomical variation or structure? Surg. Radiol. Anat., 42(1):69-74, 2020

Arruda, J. A.; Silva, P.; Silva, L.; Alvares, P.; Silva, L.; Zavanelli, R.; Rodrigues, C.; Gerbi, M.; Sobral, A.P. \& Silveira, M. Dental implant in the canalis sinuosus: a case report and review of the literature. Case Rep. Dent., 2017:4810123, 2017.

Baena-Caldas, G.; Rengifo-Miranda, H.; Heerera-Rubio, A.; Peckham, X. \& Zúñiga, J. Frequency of canalis sinuosus and its anatomic variations in cone beam computed tomography images. Int. J. Morphol., 37(3):852-7, 2019.

de Oliveira-Santos, C.; Rubira-Bullen, I. R.; Monteiro, S. A. C.; Leon, J. E. \& Jacobs, R. Neurovascular anatomical variations in the anterior palate observed on CBCT images. Clin. Oral Implants Res., 24(9):1044-8, 2013.

Gray, H.; Warwick, R. \& Williams, P. Gray's Anatomy. 35 th $e d$. Edinburgh, Longman, 1973.

Gurler, G.; Delilbasi, C.; Ogut, E. E.; Aydin, K. \& Sakul, U. Evaluation of the morphology of the canalis sinuosus using cone-beam computed tomography in patients with maxillary impacted canines. Imaging Sci. Dent., 47(2):69-74, 2017.

Jones, F. W. The anterior superior alveolar nerve and vessels. J. Anat., 73 (Pt. 4):583-91, 1939.

Landis, J. R. \& Koch, G. G. The measurement of observer agreement for categorical data. Biometrics, 33(1):159-74, 1977.

Lopes dos Santos, G.; Ikuta, C. R. S.; Salzedas, L. M. P.; Miyahara, G. I. \& Tjioe, K. C. Canalis sinuosus: An Anatomic repair that may prevent success of dental implants in anterior maxilla. J. Prosthodont., 29(9):751-5, 2020 
Machado, V. C.; Chrcanovic, B. R.; Felippe, M. B.; Manhães Junior, L. R. $\&$ de Carvalho, P. S. Assessment of accessory canals of the canalis sinuosus: a study of 1000 cone beam computed tomography examinations. Int. J. Oral Maxillofac. Surg., 45(12):1586-91, 2016.

Manhães Junior, L. R.; Villaca-Carvalho, M. F.; Moraes, M. E.; Lopes, S. L.; Silva, M. B. \& Junqueira, J. L. Location and classification of Canalis sinuosus for cone beam computed tomography: avoiding misdiagnosis. Braz. Oral Res., 30(1):e49, 2016.

Orhan, K.; Gorurgoz, C.; Akyol, M.; Ozarslanturk, S. \& Avsever, H. An anatomical variant: evaluation of accessory canals of the canalis sinuosus using cone beam computed tomography. Folia Morphol. (Warsz.), 77(3):551-557, 2018.

Schober, P.; Boer, C. \& Schwarte, L. A. Correlation coefficients: Appropriate use and interpretation. Anesth. Analg., 126(5):1763-8, 2018.

Shintaku, W. H.; Ferreira, C. F. \& Venturin, J. S. Invasion of the canalis sinuosus by dental implants: A report of 3 cases. Imaging Sci. Dent., 50(4):353-7, 2020.

Volberg, R. \& Mordanov, O. Canalis sinuosus damage after immediate dental implant placement in the esthetic zone. Case Rep. Dent., 2019:3462794, 2019.

von Arx, T.; Lozanoff, S.; Sendi, P. \& Bornstein, M. M. Assessment of bone channels other than the nasopalatine canal in the anterior maxilla using limited cone beam computed tomography. Surg. Radiol. Anat., 35(9):783-90, 2013

Wanzeler, A. M.; Marinho, C. G.; Alves Junior, S. M.; Manzi, F. R. \& Tuji, F. M. Anatomical study of the canalis sinuosus in 100 cone beam computed tomography examinations. Oral Maxillofac. Surg, 19(1):49$53,2015$.
Corresponding author:

Naira Figueiredo Deana. PT, MSc

Faculty of Dentistry

Universidad de La Frontera

1145 Francisco Salazar Avenue

PO BOX 54-D

Postal Code: 4780000

Temuco

CHILE

E-mail: n.figueiredo01@ufromail.cl

Received: 06-04-2021

Accepted: 09-05-2021 